\title{
Double plate fixation technique for prolonged non-weight baring induced severe disuse atrophy in hypertrophic non-union of left femur: a case report
}

\author{
Cokorda Gde Oka Dharmayuda*, Cokorda Krishna Dalem Pemayun, \\ I. Ketut Wahyu Trisaputra, Richard Afandi, Sri Mahadhana, Made Winatra Satya Putra, \\ I. Gusti Ngurah Indra Wiguna
}

Department of Orthopaedic and Traumatology, Sanglah Hospital, University of Udayana, Bali, Indonesia

Received: 04 August 2021

Revised: 04 September 2021

Accepted: 06 September 2021

*Correspondence:

Dr. Cokorda Gde Oka Dharmayuda,

E-mail: cdharmayuda@gmail.com

Copyright: () the author(s), publisher and licensee Medip Academy. This is an open-access article distributed under the terms of the Creative Commons Attribution Non-Commercial License, which permits unrestricted non-commercial use, distribution, and reproduction in any medium, provided the original work is properly cited.

\begin{abstract}
Hypertrophic non-union differs from other forms of non-union due to its the biological capacity for union, in which it results from mechanical instability, namely the implant being unable to provide long lasting stability. Non-weight bearing state will cause bone resorption and further bone-mass loss with worsened prognosis. A 64-year-old female patient presented with inability to walk normally resulting from prolonged non-weight bearing-induced severe disuse atrophy in hypertrophic non-union of the left femur. Implant revision and osteoclasis were performed, followed by an urgent implant revision a few days later using double plating technique by placing the second plate on the anterior part of the femur. Post-operative X-ray showed satisfactory two implants placement and physiological alignment was achieved. Inappropriate initial treatment on the acute phase has led to prolonged non weight bearing state, resulting in disuse atrophy of the bone. This should have been predicted during the first implant revision on drilling both cortices, since even the slightest distraction resulted in severe consequences. Double plating system leads to absolute stability so acceptable union can be achieved. Initial treatment on acute setting of fracture should maximize every effort to restore proper functional state and should promote early mobilization. Any maltreatment will result in prolonged morbidity and will require more reconstruction effort with less than normal end result. Robust fixation and alignment can be achieved with double plating system; however, prolonged immobilization should be anticipated.
\end{abstract}

Keywords: Disuse atrophy, Double plate fixation, Hypertrophic non-union, Prolonged non-weight bearing

\section{INTRODUCTION}

Although good outcomes femur diaphysis fractures surgery had been reported and understandings about biomechanics and improvements of implant design has been improved, non-union is still a disconcerting complication. Femoral non-union presents challenge for both surgeon and patient in terms of technical, emotional, and economic. It can be even more complicated when the bone is porotic and requires an unusual strategy for fixation. ${ }^{1,2}$
From biological point of view, repair of fractures involves a sequence of dynamic events, which ultimately restores the integrity of the bone and its biomechanical properties. ${ }^{3}$ Hypertrophic non-union differs from other forms of non-union due to its the biological capacity for union. This non-union type occurs as a result of mechanical instability, particularly when the implant is unable to provide long lasting stability. ${ }^{4}$ In this case, inappropriate plating whether poor selection of plate type or inability to achieve stable and robust compression through proper screw placement, compromise the fixation 
integrity and associated with high risk of implant failure which eventually will lead to devastating effect of nonunion. ${ }^{5}$

Non-union is generally unacceptable because it might lead to even worse functional state, where the patient won't achieve early mobilization. ${ }^{6}$ Non weight bearing state will induce bone resorption and if this condition persist, further bone-mass loss will be inevitable which eventually worsen the prognosis. ${ }^{7}$ Here we present an unusual example of a patient who underwent two stages implant revision with severe porotic femur due to neglected implant failure in left femur.

\section{METHODS}

A 64 years old female was admitted complained unable to walk normally without crutch since 2011 . The problem was said to be consistently worsen, while pain and paraesthesia along the lower extremity were denied. Patient also complained that her left leg is shorter than the right one. The problem started right after patient underwent surgery due to broken left thigh bone, which were performed in another centre on late 2011. Afterwards, patient mobilized with double axillary crutches and due to her left leg is shorter than the right one, her left foot didn't touch the ground at all ever since. No history of chronic and metabolic disease was present, no history of another trauma following the surgery was stated and there was no history of similar problem in her family. Patient is a housewife with two children and her daily activity was limited around her house.

Physical examination revealed swelling and deformity on distal left thigh with shortening and external rotation. Distal perfusion and sensory function were still preserved with leg length discrepancy was found to be $4 \mathrm{~cm}$ and active range of motion of left knee was limited. Left thigh plain radiograph showed implant failure with dislodged and headless screws embedded on the femur. Formation of callus was observed on fracture site, with thin cortices on both tensile and compression sides suggesting severe disuse osteoporosis due to hypertrophic non-union induced of left femur. What we considered as technical error was less screws and plate length on the proximal site, which could present less robust fixation according to the lever-arm concept of plate fixation (Figure $1 \mathrm{a}$ and $\mathrm{b}$ ).

Patient was scheduled to underwent surgical intervention implant revision and osteoclasis as an attempt to refresh the fracture site and to establish satisfactory fixation utilizing locking broad plate with 4.5 locking screw. Bone grafting was anticipated to fill the defect due to further shortening as consequence of callus osteoclasis on fracture site by using osteogenic callus bone graft with osteoconductive bone gross framework.

Using standard lateral approach following post op scar extending to periarticular site distally, we discovered failed implant system of compression broad plate with 4.5 screws and callus deposit on both fracture ends. Removal of failed implant followed by osteoclasis, continued with reduction and fixation with locking broad plate 10 holes and seven 4.5 locking screws on lateral side of the femur. There was a gap between the fragments after regaining optimum alignment and maximum attempt to restore symmetrical femoral length, which then be filled with osteogenic callus autograft plus osteoconductive bone graft frameworks. After a brief moment of post-operative observation, patient then proceed for post-operative X-ray evaluation.

A devastating peri-implant fracture with anterior and posterior displacement of proximal and distal fragment respectively was seen on plain radiography (Figure 2). There was no sign of implant failure, with stable configuration and appropriate screws placement were still maintained. Retrospect evaluation suggesting a very minor force applied when removing the patient from operating table was deemed to be the reason of this condition to happened even though it's very unlikely to be the cause of long bone fracture in a normal long bone, suggesting an underlying pathological condition.

An urgent implant revision was carried out a few days later, with similar surgical approach. We implemented double plating technique by placing the second plate on the anterior part of the femur with a longer 14 holes locking broad plate and 10 locking screws. A meticulous osteoclasis revealed a true cortical surface to evade misplacing the implant. Since the second implant is literally perpendicular to earlier implant on the lateral side, the plate position was arranged to avoid the anterior screws interference with the lateral screws. Osteogenic bone graft combined with synthetic osteoconductive bone graft filled the defect area in purpose to promote ossification (Figure 3). A durante op C-arm evaluation confirmed with post-operative X-ray showed satisfactory two implants placement and physiological alignment was achieved (Figure 4).

Post-operative care consisted of prophylactic course of antibiotic, epidural analgetic, and a total of three bags of packed red blood cells transfusion, followed by series of physical therapy which were initiated immediately. Non weight baring mobilization with wheelchair was proposed to eliminate further risk failure of the implant system. Pain visual analogue score post-operative was less than three and persist as invasive analgetic was removed. A significant improvement in patients complain was recorded after the second implant revision, with the patient was able to initiate mobilization with tolerable pain compared to after the first implant revision. The patient was then discharged on the fourth day after the second surgery, after receiving a detail post-operative plan on the outpatient clinics. 

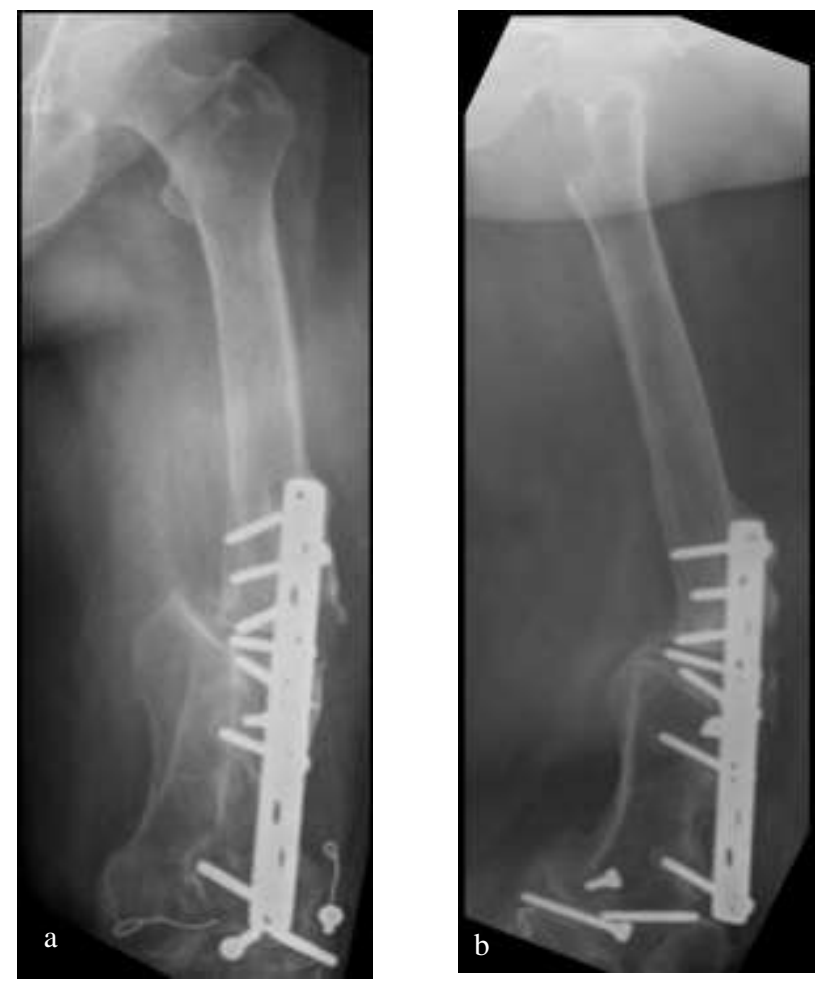

Figure 1: Patients left femur AP (a) and lateral (b) view taken on admission date.
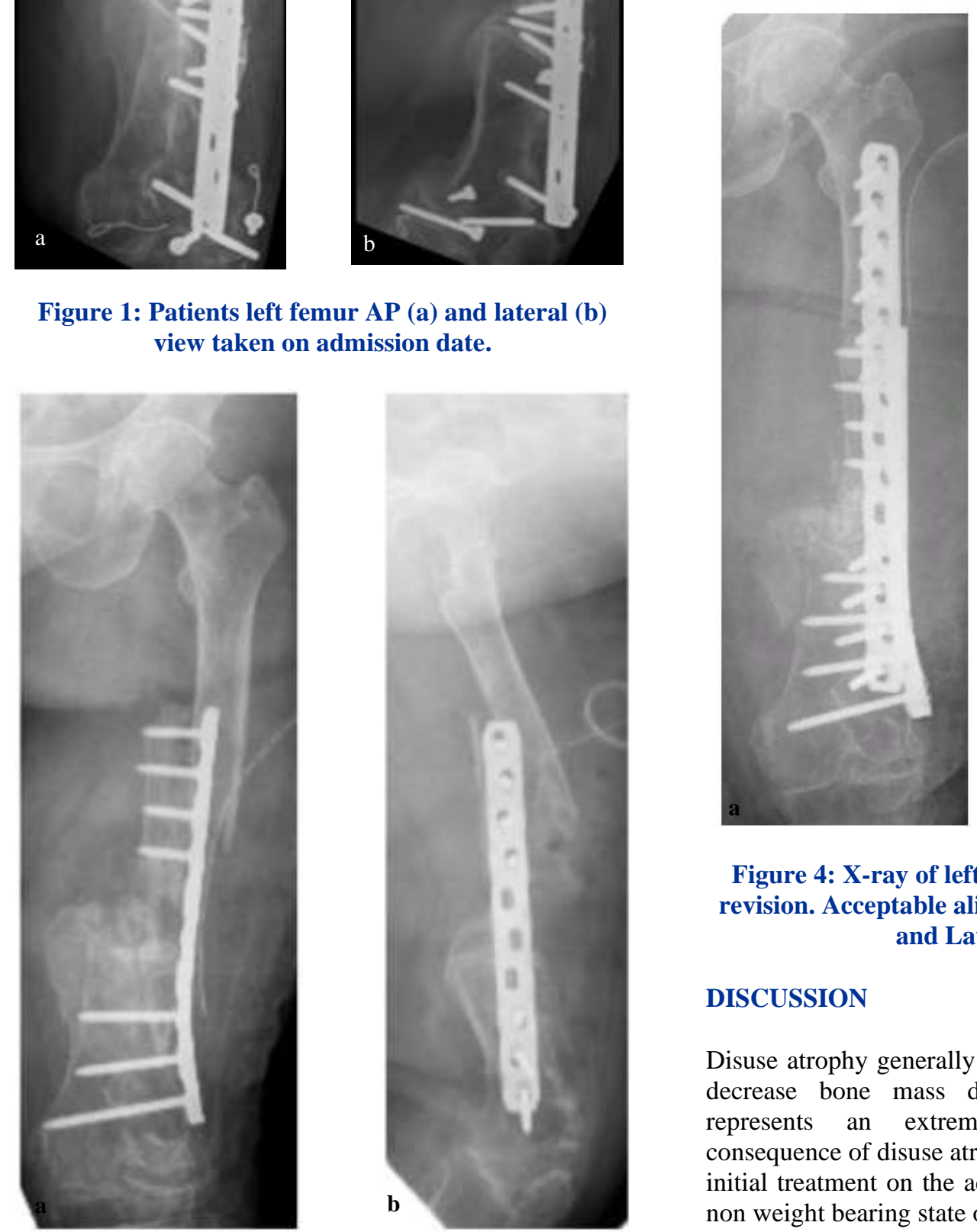

b

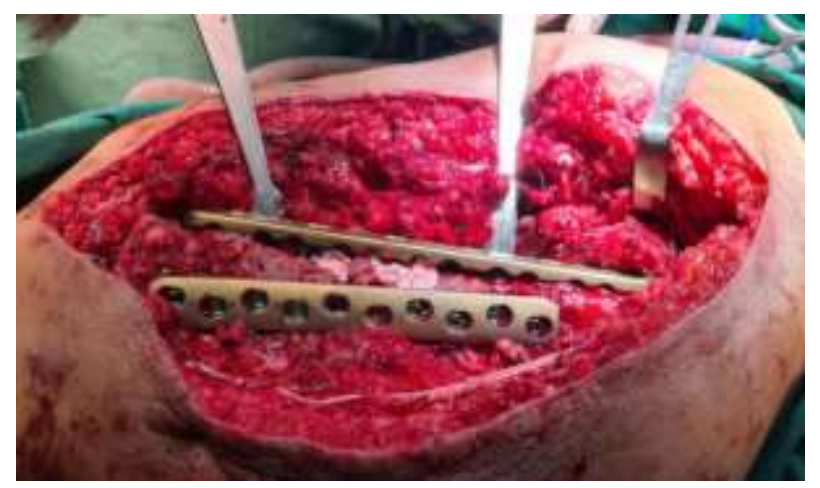

Figure 3: Durante-op showing double plating system with bone graft filled defect site.

Figure 4: X-ray of left femur after second implant revision. Acceptable alignment was shown on AP (a) and Lateral (b) view.

\section{DISCUSSION}

Disuse atrophy generally acknowledge as the etiology of decrease bone mass density, particularly this case represents an extreme example of devastating consequence of disuse atrophy of the bone. ${ }^{8}$ Inappropriate initial treatment on the acute phase has led to prolonged non weight bearing state of the patient. And subject to her awareness her bone density chronically deteriorated for around eleven years. It should have been predicted during the first implant revision on drilling both cortices, where there were minimal to non-resistance as the drill bit 
advancing. As a matter of fact, even the slightest distraction resulted in severe consequences.

Few options surfaced regarding fixation system on the second revision. In general, Intra medullary nailing considered to be the best option for failed implant, but due to its property as load sharing device, we were unsure regarding the compression resistance capability of the left femur which had been proven to be so brittle due to its unusual circumstances. ${ }^{4,9}$ Since the first implant revision was considered stable, to remove it will leave more susceptible bone prone to further damage. Thus, double platting system is applied to resist sagittal plane displacement of the fracture. This surely will leave a further non weight baring state of the left femur, but since an absolute stability was achieved so that enormous callus production indicates good biological property, a slight delay in rehabilitation is anticipated and hopefully will lead to good union with acceptable sequalae for an elder woman. ${ }^{10}$

\section{CONCLUSION}

Fracture restoration involves a sequence of dynamic measures, which ultimately reestablishes the integrity of the bone and its biomechanical properties. Initial treatment on acute setting of fracture should maximize every effort to restore proper functional state and should promote early mobilization. Any maltreatment will result in prolonged morbidity and will require more reconstruction effort with less than normal end result. This unique case of neglected implant failure of the femur resulted in prolonged immobilization and presented difficult challenge for orthopaedic surgeon to achieve optimum functional state. A total of two implant revision surgeries were carried to gain robust fixation and alignment in which were severely compromised and to promote most physiologic function possible. Prolonged immobilization is anticipated and close monitoring on post-operative treatment on clinic to confirm each development stage of fracture healing to accommodate proper rehabilitation regiment.

\section{ACKNOWLEDGEMENTS}

We would like to thank Ketut Gede Mulyadi Ridia as Head of Orthopaedics and Traumatology Department, Faculty of Medicine Udayana University, Sanglah General Hospital for all the support regarding this study.

Funding: No funding sources Conflict of interest: None declared

Ethical approval: Not required

\section{REFERENCES}

1. Lynch JR, Taitsman LA, Barei DP, Nork SE. Femoral Nonunion: Risk Factors and Treatment Options. J Am Acad Orthop Surg. 2008;16:88-97.

2. Somford MP, Kloen P, van den Bekerom MPJ. Operative treatment for femoral shaft nonunions, a systematic review of the literature. Strateg Trauma Limb Reconstr 2013;8:77-88.

3. Oryan A, Monazzah S, Bigham-sadegh A. Bone Injury and Fracture Healing Biology Bone Injury and Fracture Healing Biology. Epub ahead of print 2015. DOI: $10.3967 /$ bes2015.006.

4. Uzun M, Çakar M, Bülbül AM, Kara A. Treatment of Aseptic Hypertrophic Nonunion of the Lower Extremity with Less Invasive Stabilization System (New Approach to Hypertrophic Nonunion Treatment of Aseptic Hypertrophic Nonunion of the Lower Extremity with Less Invasive Stabilization System N. Epub ahead of print 2016. DOI: $10.1155 / 2015 / 631254$.

5. Ma Y-G, Hu G-L, Hu W, Liang F. Surgical factors contributing to nonunion in femoral shaft fracture following intramedullary nailing. Chinese J Traumatol. 2016;19:109-12.

6. Sk S. Fracture Non-Union: A Review of Clinical Challenges and Future Research Needs. 2019;13:1-10.

7. Partridge NC, Remodeling B. REVIEWS Physiological Bone Remodeling: Systemic Regulation and Growth Factor Involvement. 2021: 233-245.

8. Alexandre C, Alexandre C, Vico L. Pathophysiology of bone loss in disuse osteoporosis Pathophysiology of bone loss in disuse osteoporosis. Jt Bone Spine. 2011;78:572-6.

9. Elbarbary AN, Hassen S, Badr IT. Outcome of intramedullary nail for fixation of osteoporotic femoral shaft fractures in the elderly above 60 . Injury. 2021;52:602-5.

10. Imam MA, Torieh A, Matthana A. Double plating of intra-articular multifragmentary C3-type distal femoral fractures through the anterior approach. Eur J Orthop Surg Traumatol. 2018;28:121-30.

Cite this article as: Dharmayuda CGO, Pemayun CKD, Trisaputra IKW, Afandi R, Mahadhana S, Putra MWS, et al. Double plate fixation technique for prolonged non-weight baring induced severe disuse atrophy in hypertrophic non-union of left femur: a case report. Int J Res Med Sci 2021;9:3182-5. 